\title{
THERMAL STABILITY OF THE ULTRAFINE AMTS ALUMINUM ALLOY AFTER HIGH STRAIN-RATE DEFORMATION
}

\author{
I. G. Shirinkina, I. G. Brodova, V. V. Astafiev
}

\begin{abstract}
M.N. Miheev Institute of Metal Physics of Ural Branch of Russian Academy of Sciences, 18 S. Kovalevskoy st.,
\end{abstract} Ekaterinburg, Russian Federation

\begin{abstract}
*Corresponding author. E-mail: brodova@,imp.uran.ru; address for correspondence: 18, ul. S. Kovalevskoy, 620990, Ekaterinburg, Russian Federation. Tel.: +7 343 3783611; fax: +7 3433745244
\end{abstract}

The thermal stability of the AMts alloy obtained by dynamic channel-angular pressing (DCAP) is considered at temperatures ranging between 200 and $400^{\circ} \mathrm{C}$. The thermal stability of the structure and properties of the AMts alloy is studied by transmission and scanning electron microscopy, X-ray analysis and microhardness measurements. It is shown that the most stable structural state is obtained after one cycle of dynamic pressing. The temperature-time parameters of complex processing have been established, including dynamic pressing and annealing, which preserve the submicrocrystalline state and high properties (hardness) of the AMts alloy.

Keywords: aluminum alloy, dynamic channel-angular pressing, thermal stability, transmission electron microscopy, EBSD analysis.

DOI: $10.17804 / 2410-9908.2015 .5 .072-079$

\section{References}

1. Valiev R.Z., Estrin Yu., Horita Z., Langdon T.G., Zehetbauer M.J., Zhu Y.T. Producing bulk ultrafine-grained materials by severe plastic deformation. JOM, 2006, vol. 58, iss. 4, pp. 33-39. DOI: 10.1007/s11837-006-0213-7.

2. Murashkin M.Yu., Markushev M.V., Ivanisenko Yu.V., Valiev R.Z. Strength of commercial aluminum alloys after equal channel angular pressing (ECAP) and post-ECAP processing. Solid State Phenomena, 2006, vol. 114, pp. 91-96. DOI: 10.4028/www.scientific.net/SSP.114.91.

3. Shorokhov E.V., Zhgilev I.N., Valiev R.Z. Method for dynamic deforming of metals. RF Patent no. 2283717. Byulleten Izobreteniy. Poleznye modeli, 2006, no. 26. (In Russian).

4. Brodova I.G., Shirinkina I.G., Yablonskikh T.I., Astaf'ev V.V., Antonova O.V., Shorokhov E.V., Zhgilev I.N. Evolution of the Structure Formation during Dynamic Pressing of the AMts alloy. The Physics of Metals and Metallography, 2008, vol. 105, iss. 6, pp. 594-601. DOI: 10.1134/S0031918X08060100.

5. Brodova I.G., Petrova A.N., Shirinkina I.G. Comparing specific features of the structural formation of aluminum alloys during severe and intense plastic deformation. Izvestiya Rossiiskoi Akademii Nauk. Seriya Fizicheskaya, 2012, vol. 76, no. 11, pp. 1378-1383. (In Russian).

6. Andrievski R.A. The thermal stability of the consolidated metallic nanomaterials. Russian Chemical Reviews, 2014, vol. 83, no. 4, pp. 365-375. DOI: 10.1070/RC2014v083n04ABEH004405.

7. Rybin V.V., Zolotorevskii N.Yu., Ushanova E.A. Fragmentation of crystals upon deformation twinning and dynamic recrystallization. The Physics of Metals and Metallography, 2015, vol. 116, iss. 7, pp. 730-744. DOI: 10.1134/S0031918X1507011X.

8. Gorelik S.S., Dobatkin S.V, Kaputkina L.M. Rekristallizatsia metallov i splavov. [Recrystallization of Metals and Alloys]. M., MISIS Publ., 2005. 432 p. (In Russian).

9. Sabirov I.N., Yunusova N.F., Islamgaliev R.K., Valiev R.Z. High-strength state of a nanostructured aluminum alloy produced by severe plastic deformation. The Physics of Metals and Metallography, 2002, vol. 93, iss. 1, pp. 94-99.

10. Degtyarev M.V., Voronova L.M., Chashchukhina T.I. Grain growth upon annealing of armco iron with various ultrafine-grained structures produced by high-pressure torsion deformation. The Physics of Metals and Metallography, 2005, vol. 99, iss. 3, pp. 276-285. 
Подана в журнал: 11.09 .2015

УДК 669.715

DOI: $10.17804 / 2410-9908.2015 .5 .072-079$

\title{
ТЕРМИЧЕСКАЯ СТАБИЛЬНОСТЬ УЛЬТРАМЕЛКОЗЕРНИСТОГО АЛЮМИНИЕ- ВОГО СПЛАВА АМЦ ПОСЛЕ ВЫСОКОСКОРОСТНОЙ ДЕФОРМАЦИИ
}

\author{
И. Г. Ширинкина, И. Г. Бродова, В. В. Астафьев
}

\begin{abstract}
Федеральное государственное бюджетное учреждение науки Институт физики металлов имени М.Н. Михеева Уральского отделения Российской академии наук, ул. С. Ковалевской, 18 , Екатеринбург, Российская Федераџия
\end{abstract}

\begin{abstract}
*Ответственный автор. Электронная почта: brodova@imp.uran.ru; адрес для переписки: ул. С. Ковалевской, 18, 620990, Екатеринбург, Российская Федерация. Телефон: +7 (343) 378-36-11; факс: +7 (343) 374-52-44
\end{abstract}

Рассмотрена термическая стабильность сплава АМц, полученного динамическим канально-угловым прессованием, при нагреве в интервале температур 200-400 ${ }^{\circ} \mathrm{C}$. Изучение термической стабильности структуры и свойств сплава АМц проведены методами просвечивающей и сканирующей электронной микроскопии, рентгеноструктурного анализа и измерений микротвердости. Показано, что наиболее стабильным является структурное состояние, полученное после одного цикла динамического прессования. Установлены температурновременные параметры комплексной обработки, включающей динамическое прессование и отжиг, при которых сохраняется субмикрокристаллическое состояние и высокие значения свойств (твёрдости) сплава АМц.

Ключевые слова: алюминиевый сплав, динамическое канально-угловое прессование, термическая стабильность, просвечивающая электронная микроскопия, EBSD анализ.

\section{1. Введение}

В настоящее время для измельчения зерен Al сплавов широко применяют методы интенсивной пластической деформации (ИПД). Многочисленные работы в этой области показали их эффективность и широкий диапазон материалов, в которых создание микро-, субмикро- и наноструктур привело к существенному изменению физических и механических характеристик $[1,2]$.

В качестве одного из способов ИПД алюминиевых сплавов в данных исследованиях был использован метод динамического канально-углового прессования, разработанный в ВНИИТФ - РФЯЦ, - ДКУП [3]. При деформировании сплавов этим методом, нагружение происходит в сложных полях внешних воздействий (ударной волны и механического сдвига), при этом, реализуются скорости деформации $10^{4}-10^{5} 1 /$ c. Как показано в [4,5], в результате такого воздействия в алюминиевых сплавах формируется субмикрокристаллическая структура с размером зерна, не превышающим 600 нм, и высокой твёрдостью. Известно, что одной из важнейших задач современного материаловедения является изучение стабильности структуры и свойств субмикро- и наноматериалов [6,10].

Цель настоящей работы - изучение термической стабильности субмикрокристаллической структуры и устойчивости упрочнения в сплаве АМц, деформированном ДКУП.

\section{2. Материал и методы исследования}

Исходными заготовками для ДКУП служили образцы, диаметром 14 - 16 мм и длиной 60 - 65 мм, вырезанные из горячепрессованных прутков промышленных сплавов типа А3003 (система Al-Mn) в отожженном состоянии. В данных экспериментах начальная скорость движения образцов (V) составляла $300 \mathrm{~m} / \mathrm{c}$, а число циклов (N) через два пересекающихся канала варьировалось от 1 до 4. Отжиги деформированных образцов проводились в электро- 
печи ПМ-1,0-7 при 200, 300 и $400{ }^{\circ} \mathrm{C}$ в течение 1 и 2 ч с охлаждением на воздухе. Измерение параметра решетки и фазовый анализ образцов проводили на дифрактометре «ДРОН-3» в Со $\mathrm{K}_{\alpha}$ излучении. Расчёты осуществляли с помощью пакета программ «Profile». Микротвердость $\mathrm{H}_{\mathrm{v}}$ измеряли на приборе «ПМТ-3» при нагрузке 0,2 Н (погрешность не превышала 10\%). Электронно-микроскопические исследования выполняли на электронном просвечивающем микроскопе «ЈЕМ-200СХ». Размеры структурных составляющих деформированных образцов рассчитывали по темнопольным электронно-микроскопическим снимкам с помощью компьютерной программы «Siams-700». Измерения проводили по 20 снимкам, полученным при одном увеличении - х 30000, погрешность составляла \pm 10 нм. Для определения химического состава и морфологии структурных составляющих использовали сканирующий электронный микроскоп «Quanta-200» с приставкой EDAX. Эволюцию структуры изучали в обратно-отражённых электронах с помощью EBSD метода.

\section{3. Результаты и их обсуждение}

Для изучения термической стабильности структуры и свойств сплава АМц были выбраны образцы, полученные при разных условиях динамического прессования. Ранее [4, 5] было установлено, что уже при одном проходе ДКУП в сплаве АМц (исходная микротвердость $\mathrm{H}_{\mathrm{V}}=450 \mathrm{MПа)} \mathrm{наблюдается} \mathrm{сильное} \mathrm{измельчение} \mathrm{структуры} \mathrm{с} \mathrm{образованием} \mathrm{фрагмен-}$ тов субмикронного размера (СМК структура). Показано, что характеристики структуры (размер зерна, наличие дефектов, плотность дислокаций, соотношение малоугловых - МУГ и большеугловых - БУГ границ) зависят от условий динамического прессования и формируются либо механизмом фрагментации [7], либо динамической рекристаллизацией [8]. Эксперименты ПЭМ показали, что при $\mathrm{N}=1, \mathrm{~V}=300 \mathrm{~m} / \mathrm{c}$ образуется СМК структура, состоящая из кристаллитов, разделенных большеугловыми неравновесными границами, и субзёрн с малоугловыми границами, сформированными дислокационными сетками (Рис. 1 a).

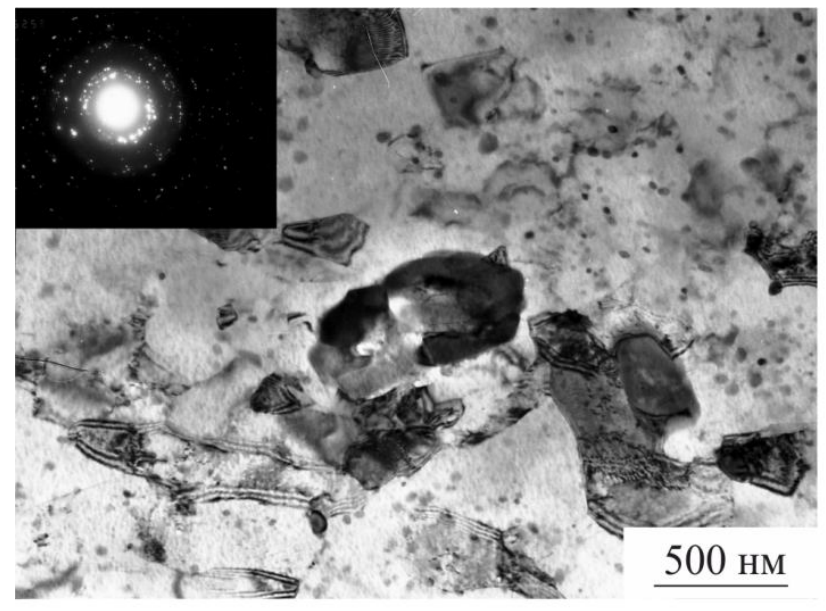

$a$

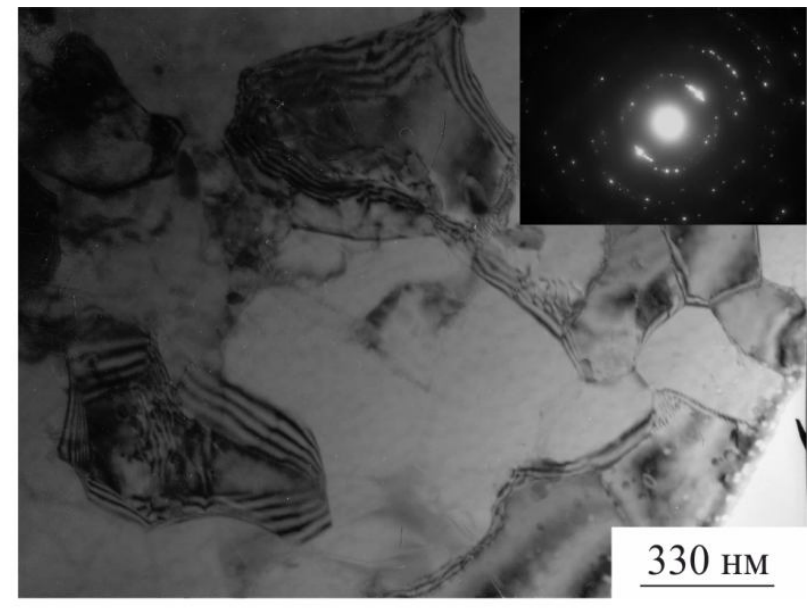

б

Рис. 1. Микроструктура сплава после ДКУП (V=300 м/с): $a-\mathrm{N}=1 ; \sigma-\mathrm{N}=4$

Кристаллиты, окружённые БУГ, формируются путем фрагментации ячеек, за счет изгиба кристаллической решетки и ротационных мод деформации. Образованная таким механизмом зёренно-субзёренная структура имеет средний размер 500-600 мкм, высокую плотность дислокаций и характеризуется повышенной в 1,5 раза относительно крупнокристаллического аналога твёрдостью. При $\mathrm{V}=300 \mathrm{~m} / \mathrm{c}$ и $\mathrm{N}=4$ СМК структура в основном состоит из кристаллитов, разделенных большеугловыми границами. На фоне мелких зёрен, свободных от дислокаций, с чётко очерченными границами, выявляются более крупные зёрна, неоднородный контраст внутри которых свидетельствует о высоком уровне внутренних напряже- 
ний. Такая разнозернистость и разный уровень упругого искажения решётки матрицы внутри кристаллитов являются типичными характеристиками смешанной структуры, образованной по механизму динамической рекристаллизации. По оценке напряжённого состояния решётки матрицы рентгеновским методом, данная структура характеризуется более низким уровнем упругих напряжений [4].

На рис. 2 a представлена структура образца после четырёхкратного прессования $(\mathrm{V}=300 \mathrm{~m} / \mathrm{c})$, полученная методом $\mathrm{EBSD}$, средний размер кристаллитов, рассчитанный по этому изображению - 570 нм. Доля большеугловых границ с углом разориентировки более 15 градусов составляет порядка $55 \%$. (рис.2 б).

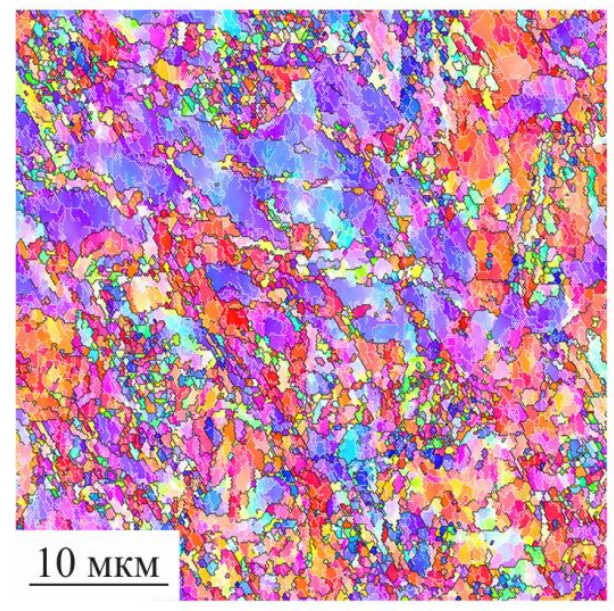

$a$

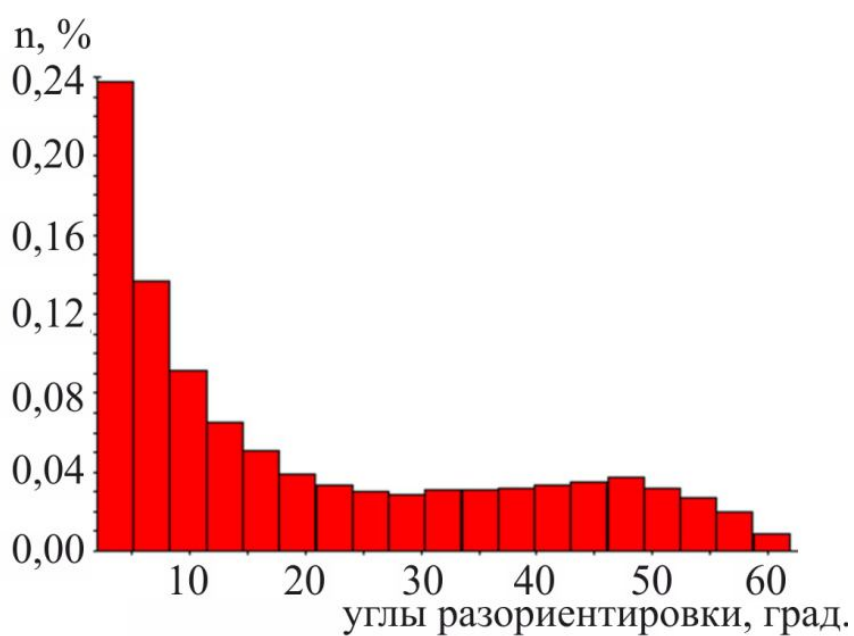

6

Рис. 2. Структура после ДКУП (V=300 м/с, N=4) в обратно отражённых электронах -

СЭМ $(a)$ и гистограмма распределения углов разориентировки кристаллитов (б)

Исследование эволюции разных деформационных структур при изохронных отжигах (1 и 2 ч) в диапазоне температур 200-400 ${ }^{\circ} \mathrm{C}$ проводилось путём сопоставления данных EBSD-анализа и измерений микротвёрдости .

На рис. 3 представлены графики изменения микротвёрдости в процессе отжигов сплава с разным типом СМК-структуры.

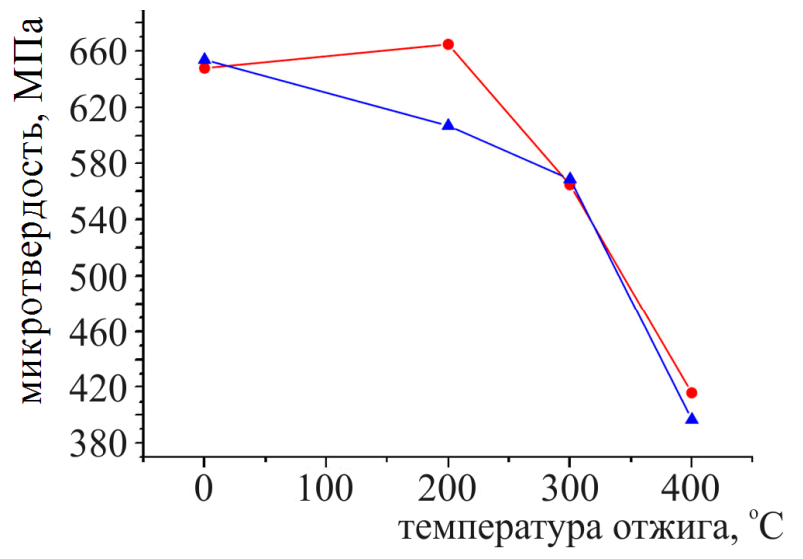

$a$

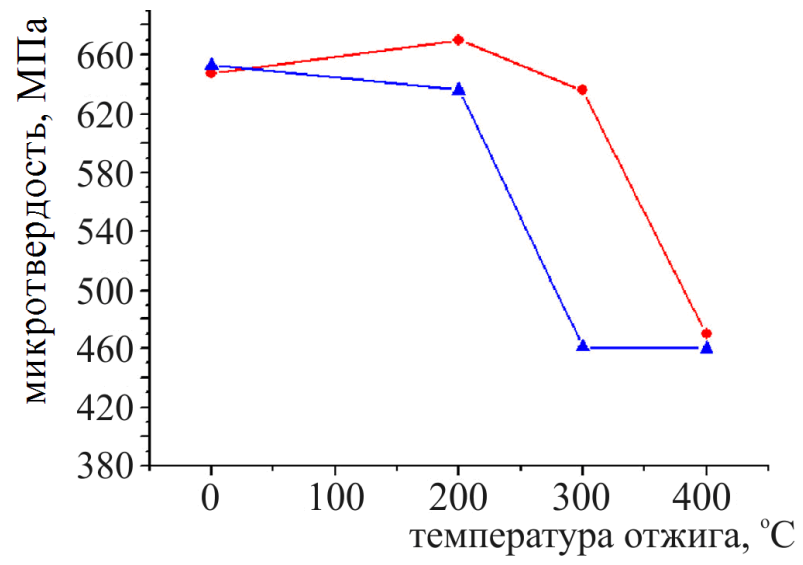

6

Рис. 3 Изменение микротвёрдости при отжиге сплава, деформированного при разных режимах динамического прессования $(\bullet-\mathrm{N}=1 ; \boldsymbol{\Delta}-\mathrm{N}=4): a$ - время выдержки 1 ч; $\sigma$ - время выдержки 2 ч 
Установлено, что материал после ДКУП сохраняет высокую твёрдость (640-580 МПа) до температуры нагрева $300{ }^{\circ} \mathrm{C}(1$ ч), причём небольшое падение твёрдости в сплаве, продеформированном многократным динамическим прессованием, начинается уже после отжига $200{ }^{\circ} \mathrm{C}$, в то время как однопроходный образец более устойчив к такому нагреву. При $400{ }^{\circ} \mathrm{C}$ твёрдость материала независимо от предыстории их обработки падает до 400-440 МПа. Увеличение времени отжига до двух часов подтвердило влияние исходной структуры на устойчивость упрочнения. Как следует из графиков, представленных на рис. 3 б, образец, СМКструктура которого сформирована механизмом динамической рекристаллизации, резко разупрочняется при нагреве до $200{ }^{\circ} \mathrm{C}$, в то время как образец с фрагментированной структурой демонстрирует высокие значения твёрдости и после отжига на $100{ }^{\circ} \mathrm{C}$ выше. При $400{ }^{\circ} \mathrm{C}$ значения микротвёрдости совпадают.

Известно, что на величину микротвёрдости материала влияют такие факторы, как размер зерна (зернограничное упрочнение) и наклёп (структурное упрочнение). Ниже приведены результаты, позволяющие оценить вклад каждого слагаемого. Учитывая, что данный сплав является термически неупрочняемым материалом, твёрдорастворное и дисперсионное упрочнения оцениваться не будут.

Изменение микроискажений решётки матрицы, отражающее уровень её напряжённого состояния, определяли по уширению рентгеновской линии (331) $\alpha$ Al матрицы (рис. 4). Уширение рентгеновского пика с ростом температуры отжига более резко изменяется для образца после одного прохода ДКУП, так как в более неравновесной и дефектной структуре, сформированной механизмом фрагментации, процессы релаксации идут быстрее.

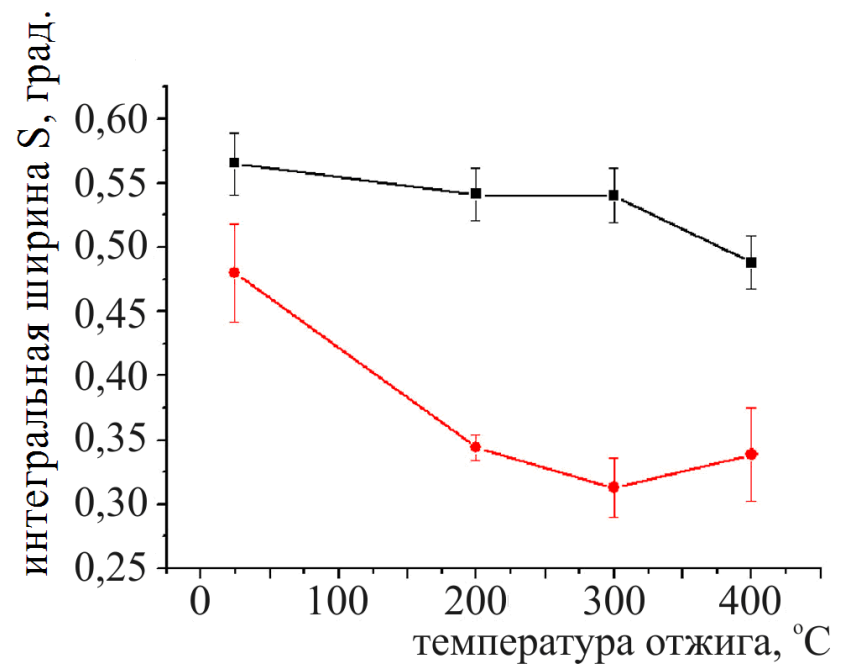

Рис. 4. Изменение интегральной ширины линии (331) $\mathrm{Al}$ матрицы от температуры отжига деформированного сплава $(\bullet-\mathrm{N}=1 ; \boldsymbol{\square}-\mathrm{N}=4)$

Для определения стабильности размера зерна при нагреве СМК-структур и оценки эволюции типов границ зёрен применён метод EBSD с использованием СЭМ.

Изменения этих характеристик после нагрева до $400{ }^{\circ} \mathrm{C}$ в образце после одного цикла ДКУП показаны на рисунке $5(a-8)$. 


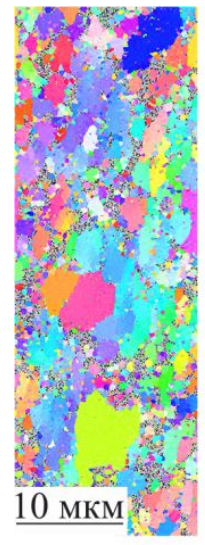

$a$

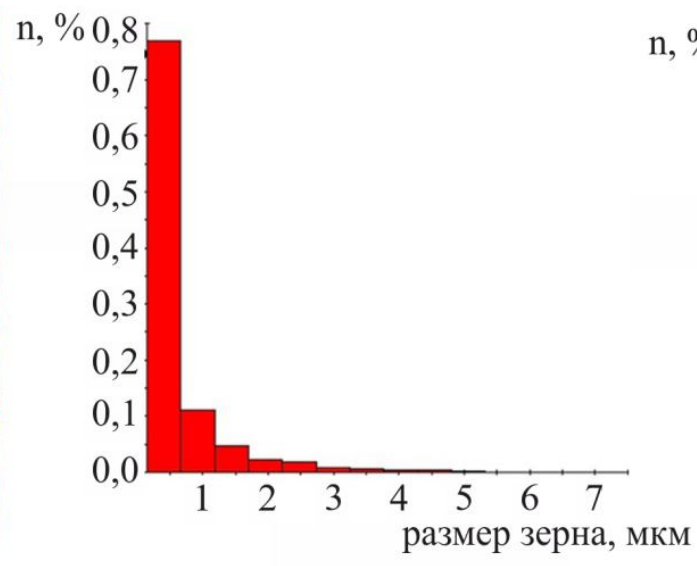

6

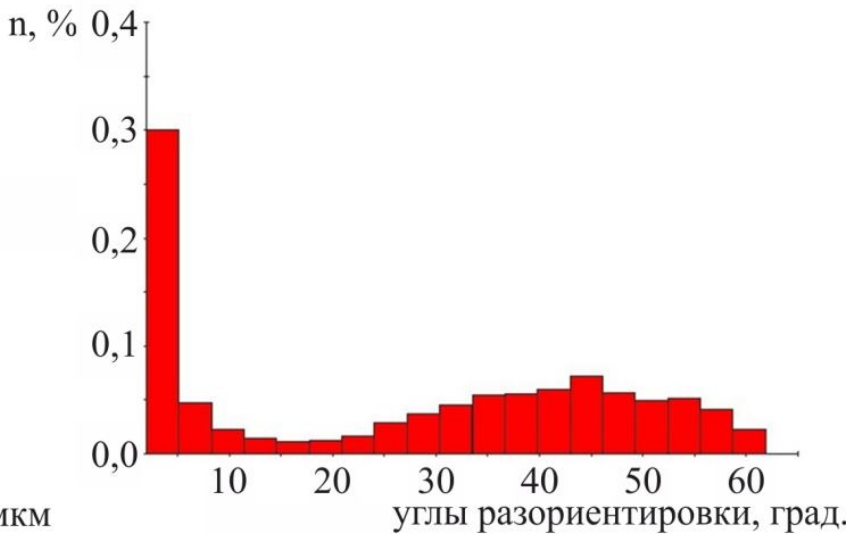

B

Рис. 5. Микроструктура отожжённого ДКУП образца $(\mathrm{N}=1)$ в обратно отражённых электронах $(a)$; гистограммы распределения зёрен по размерам (б) и углов разориентировки зёрен (в)

По этим данным средний размер зерна составил 650 нм, а соотношение малоугловых и большеугловых (с разориентировкой более 15 градусов) границ зёрен - 40/60. При сравнении с оценкой среднего размера зёренно-субзёренной структуры до отжига, по данным ПЭМ (600 нм), можно считать, что после 1-часового отжига сохраняется субмикрокристаллическое состояние материала. Структура по своим морфологическим признакам неравномерная, т. е. участки с высокой плотностью дислокаций (рис 6 a) сочетаются с “чистыми” зернами, имеющими чёткие 120-градусные границы (рис.6 б).

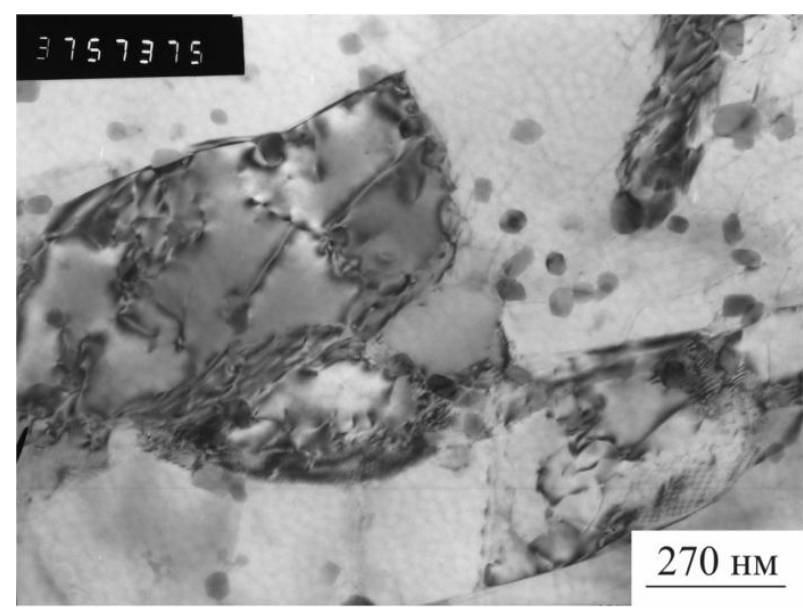

$a$

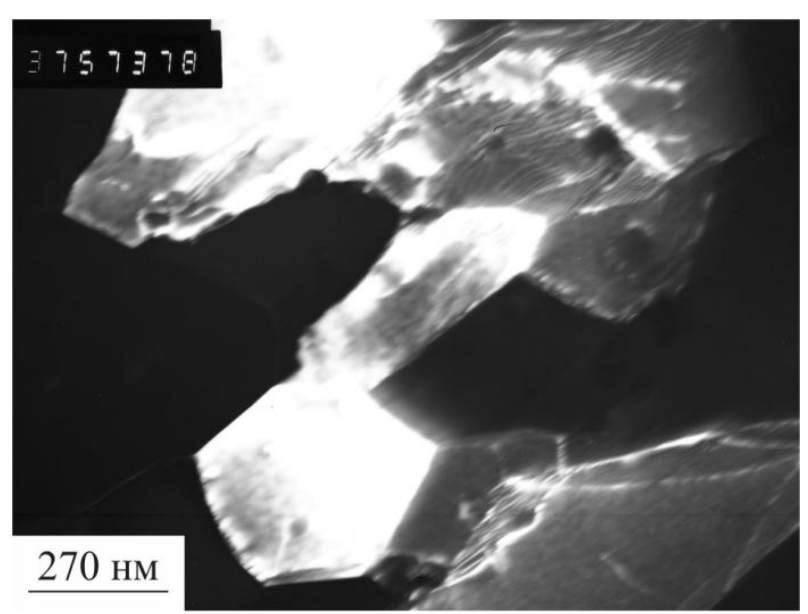

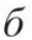

Рис. 6. Микроструктура сплава $(\mathrm{V}=300 \mathrm{~m} / \mathrm{c} \mathrm{N}=1)$ после отжига $\left(400{ }^{\circ} \mathrm{C}\right.$, время выдержки 1 ч): $a$ - светлопольное изображение; $\sigma$ - темнопольное изображение в рефлексе матрицы $(022)_{\mathrm{Al}}$

Иная ситуация наблюдается при нагреве образца после 4 циклов прессования. При $400{ }^{\circ} \mathrm{C}$ в сплаве преобладает бимодальная структура (рис. 7 a, б). Средний размер мелких зёрен составляет 325-350 нм, а крупные зёрна вырастают до десятков микрометров. 


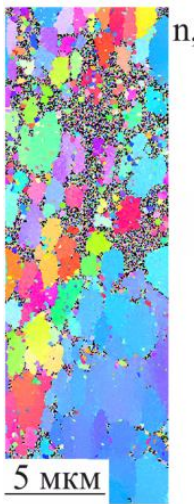

$a$

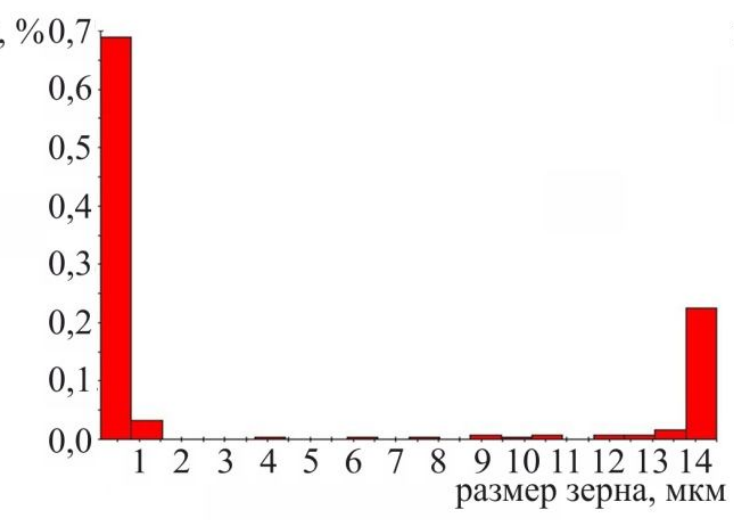

$\sigma$

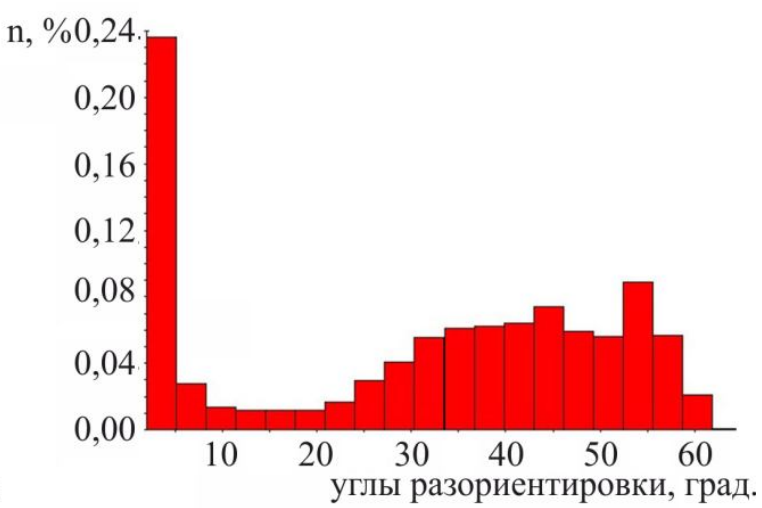

8

Рис. 7. Микроструктура отожжённого ДКУП образца $(\mathrm{N}=4)$ в обратно отражённых электронах $(a)$; гистограммы распределения зёрен по размерам (б) и углов разориентировки зёрен (в)

Рис. 7 в иллюстрирует соотношение малоугловых и большеугловых границ, наблюдаемых в структуре отожжённого образца. Если их сравнить с данными рис. 2 б, то получается, что после отжига доля МУГ в структуре сплава уменьшается почти вдвое, а доля БУГ возрастает до $72 \%$.

Таким образом, наибольшая стабильность размера зерна при отжиге выявлена в материале после одного цикла ДКУП, структура которого сформирована механизмом фрагментации. Сравнение морфологии структурных характеристик этого образца после деформации и после отжига позволяет заключить, что при нагреве основным постдеформационным процессом является возврат неравновесных границ и аннигиляция дефектов. Высокое зернограничное упрочнение компенсирует частичную релаксацию напряжений и сохраняет высокие значения твёрдости при последующей после ДКУП термической обработке.

В образце, полученном четырёхкратным прессованием, наряду с возвратом наблюдается миграция неравновесных границ и аномальный рост зёрен, причём последний при температурах отжига выше $200{ }^{\circ} \mathrm{C}$ становится преобладающим релаксационным процессом. Падение твёрдости материала с такой структурой происходит в основном за счёт снижения зернограничного упрочнения. Важно отметить, что такой необычный характер роста зёрен при отжиге является отличительной чертой структуры, образованной интенсивной пластической деформацией $[8,9]$.

\section{4. Заключение}

Методами просвечивающей и сканирующей электронной микроскопии изучена термическая стабильность структуры и свойств сплава АМц в субмикрокристаллическом состоянии, полученном динамическим прессованием. Показано, что зёренно-субзёренная структура, со средним размером 600 нм, стабильна при нагреве до $400{ }^{\circ} \mathrm{C}$.

Построены температурные зависимости твёрдости материала для разных структурных состояний и установлено, что деформированный материал сохраняет высокую твёрдость 640-580 МПа при одночасовом отжиге до $300{ }^{\circ} \mathrm{C}$.

Проанализированы причины термической устойчивости упрочнения субмикрокристаллического сплава. Показано, что снижение твёрдости сплава с фрагментированной структурой происходит за счёт уменьшения вклада от структурного упрочнения. Разупрочнение СМК-структуры, полученной динамической рекристаллизацией, происходит в основном за счёт уменьшения зернограничной составляющей. 


\section{Благодарность}

Электронно-микроскопические исследования выполнены в отделе электронной микроскопии ЦКП ИФМ УрО РАН «Испытательный центр нанотехнологий и перспективных материалов».

Работа выполнена при финансовой поддержке Программы Уральского Отделения РАН (проект №15-17-2-9).

\section{Литература}

1. Producing bulk ultrafine-grained materials by severe plastic deformation / R. Z. Valiev, Yu. Estrin, Z. Horita, T. G. Langdon, M. J. Zehetbauer, Y. T. Zhu // JOM. - 2006. - Vol. 58, iss. 4. - P. 33-43. - DOI: 10.1007/s11837-006-0213-7.

2. Strength of commercial aluminum alloys after equal channel angular pressing (ECAP) and post-ECAP processing / M. Yu. Murashkin, M. V. Markushev, Yu. V. Ivanisenko, R. Z. Valiev // Solid State Phenomena. - 2006. - Vol. 114. - P. 91-96. DOI: $10.4028 /$ www.scientific.net/SSP.114.91.

3. Способ динамической обработки материалов : пат. 2283717 Рос. Федерации / Шорохов Е. В., Жгилев И. Н., Валиев Р. З. - № 2004131484/02; заявл. 28.10.04; опубл. 20.09.06, Бюл. № 26. - 5 с.

4. Evolution of the Structure Formation during Dynamic Pressing of the AMts alloy / I. G. Brodova, I. G. Shirinkina, T. I. Yablonskikh, V. V. Astaf'ev, O. V. Antonova, E. V. Shorokhov, I. N. Zhgilev // The Physics of Metals and Metallography. - 2008. - Vol. 105, iss. 6. - P. 594-601. DOI: $10.1134 / \mathrm{S} 0031918 X 08060100$.

5. Бродова И. Г., Петрова А. Н., Ширинкина И. Г. Сравнение закономерностей формирования структуры алюминиевых сплавов при большой и интенсивной пластической деформации // Известия РАН. Серия физическая. - 2012. - Т. 76, № 11. - С. 1378-1383.

6. Andrievski R. A. The thermal stability of the consolidated metallic nanomaterials // Russian Chemical Reviews. - 2014. - Vol. 83, no. 4. - P. 365-375. DOI: 10.1070/RC2014v083n04ABEH004405.

7. Rybin V. V., Zolotorevskii N. Yu., Ushanova E. A. Fragmentation of crystals upon deformation twinning and dynamic recrystallization // The Physics of Metals and Metallography. - 2015. - Vol. 116, iss. 7. - P. 730-744. - DOI: 10.1134/S0031918X1507011X.

8. Горелик С. С., Добаткин С. В., Капуткина Л. М. Рекристаллизация металлов и сплавов. - 3-е изд. - М. : МИСиС, 2005. - 432 с.

9. High-strength state of a nanostructured aluminum alloy produced by severe plastic deformation / I. N. Sabirov, N. F. Yunusova, R. K. Islamgaliev, R. Z. Valiev // The Physics of Metals and Metallography. - 2002. - Vol. 93, iss. 1. - P. 94-99.

10. Degtyarev M. V., Voronova L. M., Chashchukhina T. I. Grain growth upon annealing of armco iron with various ultrafine-grained structures produced by high-pressure torsion deformation // The Physics of Metals and Metallography. - 2005. - Vol. 99, iss. 3. - P. 276-285. 